\title{
TOP CITED PAPERS IN INTERNATIONAL PSYCHOGERIATRICS: 1. LONG-TERM USE OF RIVASTIGMINE IN PATIENTS WITH DEMENTIA WITH LEWY BODIES: AN OPEN-LABEL TRIAL
}

\section{Reflection}

Eleven authors, 29 patients and an open-label design would not generally be regarded as strong predictors of a publication's citation success, so this one (Grace et al., 2001) probably needs some explaining. I was advised early in my prospective publishing career always to look for "a gap in the market" and in 2001 this short paper probably filled a significant gap in clinical knowledge. It was almost a decade since the first reports had appeared about dementia with Lewy bodies (DLB) being a relatively common cause of dementia in older people, and by 2001 the first iteration of the consensus criteria for DLB diagnosis was starting to be widely used. Clinicians were therefore becoming more confident about recognizing DLB in their clinics, realized that cholinesterase inhibitors (ChEIs) were often useful in symptom control, and wanted to know more about their effects in the longer term. This short paper gave them some useful evidence to support their practice. The lead author, Janet Grace, who was working as my clinical lecturer, had for a couple of years been following up a group of DLB patients whom she had originally entered in an earlier placebo controlled study (McKeith et al., 2000) and was interested in charting their progress with the ready help of U.K. colleagues in Essex, Manchester, Southampton and Nottingham. Although the 21 patients who remained on treatment did show some evidence of disease progression after two years, neither their Mini-mental State Examination (MMSE) scores nor their Neuropsychiatric Inventory (NPI) scores were significantly worse than at baseline. And reassuringly their parkinsonism had not worsened, which was a common concern at that time.

Gratifying as it is for our paper to top the International Psychogeriatrics citation list, it is also a paradoxical indicator that not a great deal of additional research on the treatment of DLB has appeared since. We have continued to publish open-label treatment studies suggesting that the profile of side effects of ChEIs in DLB differs from Alzheimer's disease, particularly with respect to autonomic dysfunction (Thomas et al., 2005). Rapid deterioration on sudden withdrawal of treatment may occur (Minett et al., 2003) and dose escalation, if tolerated, can produce clinical benefits in non-responders (Pakrasi et al., 2006). ChEIs are widely given to DLB patients in most countries, but such prescribing remains off-license and there is still a dearth of information about their use in this population. As the current generation of antidementia drugs approach their patent expiry dates it seems unlikely that pharmaceutical company sponsorship will be forthcoming to support the trials necessary for DLB to become a licensed indication. Now is the time to start approaching other funding sources to support such studies. And as new agents for the treatment of dementia appear, we must ensure that DLB has a prominent place in their development programs.

\author{
IAN MCKEITH \\ Professor of Old Age Psychiatry and Clinical Director \\ Institute of Ageing and Health, Newcastle University. \\ Newcastle upon Tyne, U.K. \\ Email: I.G.McKeith@newcastle.ac.uk
}

\section{Commentary}

With 57 citations to the end of 2006, the paper of Grace et al. (2001) on which Ian McKeith was senior author was a clear winner by eight citations from its nearest rival in a very impressive issue of International Psychogeriatrics, which also saw publication of the fifth most highly cited paper (Manes et al. 2001) in our history (Ames, 2009). Perhaps one reason why all eight top papers clustered in the years $2000-2002$ is that the journal only acquired an impact factor in 2002, so that papers published in the years 1989-1999 were comparatively disadvantaged (although the journal's citations are known to have a relatively long half-life), while those published in subsequent years have not had so long a period of time in which to accumulate citations. Nevertheless, it is no small achievement for any paper to garner 57 citations within four and a half years of publication (the 2006 citation index considered only papers published in 2005 and earlier). 
I think that a combination of reasons account for the high citation rate of this concise and wellwritten descriptive study. McKeith is right to note its relatively unique character. In addition, dementia with Lewy bodies (DLB) is very obviously an important illness, not only correctly to diagnose lest one poison the patient with neuroleptics due to misdiagnosis, but also because there is so much potential for the clinician to do good. Unlike the modest benefits seen when Alzheimer's disease is treated with a cholinesterase inhibitor (ChEI), DLB is perhaps the only neurodegenerative disease routinely treated by psychiatrists in which some (not all) patients exhibit a remarkable degree of improvement when medicated. Those of us who have seen such phenomena in our clinical practice are keen to cite whatever published evidence is available to confirm the veracity of our observations. McKeith and colleagues deserve the thanks of all people with DLB and Parkinson's disease dementia (PDD) for turning what used to be established wisdom on its head and demonstrating that cholinergic transmission does not need to be blocked when Lewy bodies are present, but enhanced. In the impressive body of work that has emanated from Newcastle upon Tyne since DLB was first described, later defined and subsequently refined, the paper of Grace et al. (2001) occupies a place out of proportion to the relatively small number of patients it describes. The importance of DLB and its treatment within the discipline of psychogeriatrics is further emphasized by the fact that the next in the "for debate" series of articles to be published in this journal will deal with the relationship between DLB and PDD, while the most recent previous debate that we published dealt with the evidence for the utility of ChEIs themselves (Ames et al., 2008). Neatly, our most cited paper links these two important and much discussed subjects, and perhaps that as much as anything else explains its remarkable and well-justified preeminence.

\section{DAVID AMES}

Editor-in-Chief International Psychogeriatrics, Melbourne, Australia

Email: ipaj-ed@unimelb.edu.au

\section{References}

Ames, D. (2009). International Psychogeriatrics comes of age. International Psychogeriatrics, 21, 1-4.

Ames, D., Kaduszkiewicz, H., van Den Bussche, H., Zimmermann, T., Birks, J. and Ashby, D. (2008). For debate: is the evidence for the efficacy of cholinesterase inhibitors in the symptomatic treatment of Alzheimer's disease convincing or not? International Psychogeriatrics, 20, 259-292.

Grace, J. et al. (2001). Long-term use of rivastigmine in patients with dementia with Lewy bodies: an open-label trial. International Psychogeriatrics, 13, 199-205.

Manes, F., Jorge, R., Morcuende, M., Yamada, T., Paradiso, S. and Robinson, R.G. (2001). A controlled study of repetitive transcranial magnetic stimulation as a treatment of depression in the elderly. International Psychogeriatrics, 13, 225-231.

McKeith, I.G. et al. (2000). Efficacy of rivastigmine in dementia with Lewy bodies: a randomised, double-blind, placebo-controlled international study. Lancet, 356, 2031-2036.

Minett, T.S.C. et al. (2003). What happens when donepezil is suddenly withdrawn? An open label trial in dementia with Lewy bodies and Parkinson's disease with dementia. International fournal of Geriatric Psychiatry, 18, 988-993.

Pakrasi, S. et al. (2006). Cholinesterase inhibitors in advanced dementia with Lewy bodies: increase or stop? International fournal of Geriatric Psychiatry, 21, 719-721.

Thomas, A.J. et al. (2005). A comparison of the efficacy of donepezil in Parkinson's disease with dementia and dementia with Lewy bodies. International fournal of Geriatric Psychiatry, 20, 938-944. 